\title{
Geographic information system for bloom monitoring inland water bodies
}



\author{
Dontsov A.A. ${ }^{1 *}$, Sutorihin I.A. ${ }^{1,2}$, Frolenkov I.M. ${ }^{1}$ \\ ${ }^{1}$ Institute for Water and Environmental Problems, Siberian Branch of the Russian Academy of Sciences, 1 Molodezhnaya Str., \\ Barnaul, 656038, Russia \\ ${ }^{2}$ Institute of Computational Technologies, Siberian Branch of the Russian Academy of Sciences, 6 Akademik Lavrentiev Prospect, \\ Novosibirsk, 630090, Russia
}

\begin{abstract}
Blooming of inland water bodies is caused by the intensive development of phytoplankton cells in the surface layer of water bodies, as a rule, in summer. Therefore, the development of methods for controlling this process is relevant. One of the methods for assessing the flowering intensity is based on determining the concentration of chlorophyll $a$, which allows obtaining objective information about the intensity of photosynthesis and phytoplankton biomass and the quality characteristics of the surface water layer. In this work, an assessment is made of the spatial content of chlorophyll $a$ in the surface layer of water bodies: the Novosibirsk reservoir, lakes Krasilovskoe and Itkul (Altai Territory) in 2017, 2018 according to the data of the spacecraft Sentinel-2 and the results of local sampling and analysis of water. Data processing processes and presentation of calculation results are implemented in the form of a geoinformation web-system. This allows you to automate the computing processes and organize access to data.
\end{abstract}

Keywords: GIS, Sentinel-2, ACOLITE, phytoplankton, water bodies, chlorophyll $a$

\section{Introduction}

Solving the problem of an operational assessment of the state of environmental objects, including aquatic ecosystems, is an urgent task. In this direction, new methodological approaches are needed the development of effective methods and measuring complexes for the implementation of the goals of environmental monitoring. As you know, the determination of the concentration of chlorophyll $a$ in water bodies, a photosynthetic pigment of a plant cell, allows one to obtain objective information about the intensity of photosynthesis and phytoplankton biomass, water quality characteristics, and the presence of chemical contamination. Satellite multispectral data make it possible the concentration of chlorophyll $a$ in the surface layer of water bodies (Boronina et al., 2014; Sukhorukov et al., 2017).

\section{Materials and methods}

In this work, an assessment is made of the spatial content of chlorophyll $a$ in the surface layer of water bodies: the Novosibirsk reservoir, lakes Krasilovskoe and Itkul (Altai Territory) in 2017, 2018 according to the data of the Sentinel-2 spacecraft and the results of local sampling of water samples. Sentinel-2 spacecraft data processing can be divided into the following base steps.

1. Preprocessing data.

2. Atmospheric correction.

3. Calculation of the concentration of chlorophyll a in the surface layer of water.

4. Georeferencing and export of the obtained results in the Geotiff format.

To implement the stages, the ACOLITE computing package was used, designed for processing Landsat (5/7/8) and Sentinel-2 (A/B) data. ACOLITE allows for atmospheric correction according to the "Dark spectrum fitting" algorithm and contains a set of algorithms for determining the concentration of chlorophyll $a$ in the surface layer of inland water bodies (ACOLITE). This computer complex can operate as a set of program libraries. Based on this, an independent module of the geoinformation system for monitoring the parameters of inland water bodies was developed. The chl_o2 module was used to calculate the chlorophyll $a$ concentration. In addition to calculating the concentration, the GIS implements the function of calculating the spectral index NDCI (Levin and Kopelevich, 2007). Which allows for a quick assessment of the chlorophyll content in a short time.

*Corresponding author.

E-mail address: alexdontsov@yandex.ru (A.A. Dontsov)

(C) Author(s) 2020. This work is distributed under the Creative Commons Attribution 4.0 License. 


\section{Results}

The results of chlorophyll determination from satellite data and the results of the NDCI calculation were compared with the data of expeditionary measurements, which took place on August 16, 2017 at the Novosibirsk reservoir. The comparison showed a rather high correlation coefficient between the results of satellite data processing and expeditionary measurements = 0.93 and. $=0.95$. For lake Krasilovskoe, the correlation coefficients are $=0.89$ and. $=0.92$ (2018, Summer). For lake Itkul, the correlation coefficients are $=0.91$ and. $=0.93$ (2018, Summer) (Dontsov and Sutorikhin, 2017). The Table shows a comparison of expeditionary data and the results of processing satellite data for the Novosibirsk reservoir. The discrepancy between satellite measurements and expeditionary data may be due to the specifics of water bodies and methods of data processing and measurement. The accuracy of estimating the concentration of chlorophyll $a$ in the surface layer depends on the atmospheric processes at the time of measurements, data processing algorithms and the time of day in which satellite measurements were obtained (Dontsov et al., 2019).

\section{Conclusions}

The relatively high correlation coefficients between the results of satellite data processing and expeditionary data show that satellite data can be used to estimate the chlorophyll $a$ content in lakes and reservoirs. The implementation of computing processes in a geographic information system allows you to automate data processing and organize access to data.
Table. Summary table of comparison of expeditionary measurements and satellite data processing results

\begin{tabular}{|c|c|}
\hline $\begin{array}{c}\text { Expeditionary measurements } \\
\left(\boldsymbol{m} \boldsymbol{g} / \boldsymbol{m}^{3}, \mathbf{1 6 . 0 8 . 2 0 1 7}\right)\end{array}$ & $\begin{array}{c}\text { Sentinel-2 } \\
\left(\boldsymbol{m g} / \boldsymbol{m}^{3}, \mathbf{2 9 . 0 8 . 2 0 1 7}\right)\end{array}$ \\
\hline Minimum $=6.99$ & Minimum $=5.67$ \\
Maximum $=35.35$ & Maximum $=29.87$ \\
Mean $=23.07$ & Mean $=22.40$ \\
\hline
\end{tabular}

\section{References}

ACOLITE [Electronic resource]. http://www.odnature. naturalsciences.be

Boronina L., Sadchikov P., Tazhieva S. et al. 2014. Effectiveness of the automation selection of water treatment technology in a particular water source. Advanced Materials Research 1073-1076: 1039-1042. DOI: 10.4028/www. scientific.net/AMR.1073-1076.1039

Dontsov A.A., Sutorikhin I.A. 2017. Specialized geoinformation system for automated monitoring of rivers and reservoirs. Computational Technologies 22(5) 39-46. (in Russian)

Dontsov A.A., Sutorikhin I.A., Frolenkov I.M. 2019. Monitoring of bloom of inland water bodies using satellite data. In: The XXV International Symposium "Atmosphere and Ocean Optics. Physics of the atmosphere", pp. 406-409. (in Russian)

Levin I.M., Kopelevich O.V. 2007. Correlation relations between primary hydro-optical characteristics in the spectral range of about $550 \mathrm{~nm}$. Okeanologiya [Oceanology] 47(3): 374-379. (in Russian)

Sukhorukov B.L., Kovaleva G.E., Novikov I.V. 2017. Evaluation of the trophicity of water bodies based on highresolution remote spectrometry data in the visible range. Vodnyye Resursy [Water Resources] 44(1): 79-90. (in Russian) 